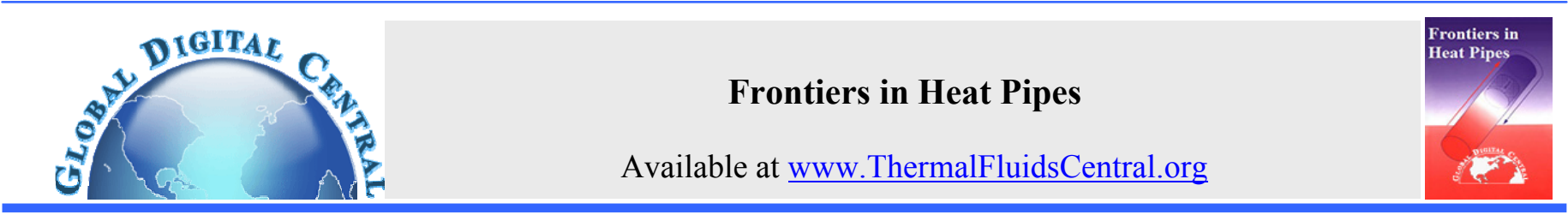

\title{
THERMAL PERFORMANCE OF VAPOR CHAMBER WITH NANOFLUIDS
}

\author{
K.N. Shukla*, A. Brusly Solomon and B.C. Pillai \\ Karunya University, Karunya Nagar, Coimbatore-641 114, India
}

\begin{abstract}
The paper describes experimental studies on the heat transfer performance of a wickless vapor chamber with a heat sink. A vapor chamber of $78 \mathrm{~mm}$ length and $64 \mathrm{~mm}$ width was fabricated with a thickness of $5 \mathrm{~mm}$ and tested for two different working fluids, copper-water and aluminium-water nanofluids with the filling ratio of $30 \%$ of the vapor chamber volume. As a baseline comparison de-ionized (DI) water is considered as a working fluid. The vapor chamber was tested for heat inputs ranging from $90-150 \mathrm{~W}$. The effects of heat input and metal concentration in the working fluids and the effect of particle deposition on the performance of the vapor chamber are presented. The thermal resistance of vapor chamber was decresed with the increase of the heat input for copper-water nanofluids while it remained constant for DIwater. Also the thermal resistance was found to be lower for higher concentration of the nanofluid.
\end{abstract}

Keywords: Vapor chamber, heat sink, nanofluids, thermal resistance.

\section{INTRODUCTION}

Future electronic systems especially computers and communication equipment are expected to be of small size, lightweight but with compact components that release very high magnitudes of heat. These miniaturized systems generate large heat fluxes during operation, which warrant the development of efficient thermal management systems. Different modules like heat pipes, heat sinks, heat spreaders and vapor chambers are used to remove inevitable hotspots in the electronic systems as presented by Shukla (1981, 2008, and 2009). Vapor chambers have been mostly used in the base of the heat sinks and they work as heat spreaders to spread the heat from the hotspots and eventually dissipate it to environment. These vapor chambers offer low thermal resistances as compared with solid heat sinks. A vapor chamber is a vacuum vessel with a wick structure lining inside the walls which in turn is saturated with a working fluid. As heat is applied, the fluid at that location immediately vaporizes and the vapor rushes to fill the vacuum. Wherever the vapor comes into contact with a cooler wall surface it condenses, releasing its latent heat of vaporization. The first experimental analysis of a flat plate heat pipe or vapor chamber was reported by Wang and Vafai (2000). Nguyen et al. (2000) showed that the performance of the heat sink and vapor chamber is approximately 25 to $45 \%$ better than a conventional heat sink with copper and aluminium heat spreaders. Subsequently there have been many investigations on vapor chambers employing different working fluids for various geometries and wick structures. For example, Xuan et al. (2004) conducted an experiment with the addition of sintered layer at the evaporator section of the flat heat pipe. It was found that, the sintered layer in the evaporator section of the heat pipe accelerated the boiling process leading to performance enhancement of the flat heat pipe. Go(2005) investigated the thermal performance of an acetone-charged vapor chamber heat sink containing micro wick structures for cooling microprocessors in PC desktop applications. In this experiment, the wick was modified to obtain a high aspect ratio of the micro channel. Three metal-etched wick plates were stacked and inserted into the 2 $\mathrm{mm}$ high vapor chamber. Cooling performance was examined by measuring the working temperatures and thermal resistances for the various heat inputs and three different tilt angles. It was concluded that the stacked metal-etched micro wick structure can provide capillary pressure sufficient to exceed the pressure drops. Carbajal et al. (2006) analysed the temperature distribution of flat heat pipes with aluminium sandwich wick and compared the performance of the vapor chamber with a copper block. It was found that the temperature at the bottom surface of the vapor chamber is much flatter than that of the solid copper block. Kang et al. (2012) carried out CFD simulation to study the temperature uniformity of vapor chamber heat spreader.

In order to improve the axial and radial heat transfer, Ming et al. (2009) constructed a grooved evaporator section in the vapor chamber and studied its performance under various conditions. Wong et al. (2010) tested a novel vapor chamber with modified evaporator and condenser. In this vapor chamber, parallel grooves are made on the inner surface of the top plate (condenser) with inter-groove openings, to replace the conventional porous wick and found that the evaporation and condensation heat transfer coefficients decreased with increasing heat loads. They also found that the evaporationresistance dominated the vapor chamber resistance. In the tested case the convectional heat transfer coefficients associated with evaporation were a few times larger than those associated with 
condensation. Choi (1995) showed that the thermo physical properties of the fluids were improved by adding ultra-fine metal particles with ordinary fluids. This followed by several studies using nano- particles suspension to improve the performance of heat transfer devices such as heat pipes, pulsating heat pipes, grooved surfaces, flat heat pipes etc. (see, Yang et al., 2008; Liu et al., 2007; Naphonet al., 2008; Qu et al., 2010; Do and Jang 2010). Very recently nanofluids have been used in the micro grooved flat heat pipe (Hyang and Jang, 2010). The thermal performance of a flat micro-heat pipe was investigated for a working fluid consisting of nano particles-alumina suspensions. Shukla et al. $(2010,2012)$ found $14 \%$ heat transfer enhancement in cylindrical heat pipes with nanofluids.

Vapor chamber heat sinks can use a variety of working fluids, depending on the operating temperature. The thermodynamic properties of water make it an order of magnitude better than any other fluid for majority of electronics cooling applications (Shukla et al. 2009). From these studies, it was understood that the thermal resistance of heat transfer devices can be reduced or heat transfer capacity can be increased by using nanofluids as working fluids.

The paper describes the experimental studies on the heat transfer performance of the vapor chamber with a heat sink using nanofluids as its working fluid. The main purpose of the study is to reduce the total thermal resistance of the heat sink by varying the working fluids of the vapor chamber.

\section{ANALYTICAL MODEL OF VAPOR CHAMBER}

An analytical model based on the method of equivalent thermal resistances was developed to estimate the overall heat transfer coefficient of the vapor chamber heat sink. The total thermal resistance is sum of the several resistances, expressed by the following equation,

$R_{\text {tot }}=R_{\text {sp }}+R_{\text {boil }}+R_{\text {cond }}+R_{\text {diss }}$

The spreading resistance, $R_{s p}$ is determined by the method given by Simons (2004),

$R_{s p}=\frac{\psi_{\max }}{k_{1} r_{1} \sqrt{\pi}} ; \psi_{\max }=\frac{\varepsilon \tau}{\sqrt{\pi}}+\frac{1}{\sqrt{\pi}}(1-\epsilon) \varphi$

$\varphi=\frac{\tanh (\lambda \tau)+\frac{\lambda}{B i}}{1+\frac{\lambda}{\mathrm{Bi}} \tanh (\lambda \tau)}$

where,

$r_{1}=\sqrt{\frac{A_{b}}{\pi}}, \quad r_{2}=\sqrt{\frac{A_{h}}{\pi},}$

$\lambda=\pi+\frac{1}{\epsilon \sqrt{\pi}}, B i=\frac{h R}{k}$

The thermal resistance due to boiling heat transfer is determined by the method proposed by Kattan et al. (1998). The method is based on two-phase flow pattern map for horizontal evaporating flows:

$R_{\text {boil }}=\frac{1}{A_{b} h_{\text {boil }}}$

Where

$h_{\text {boil }}=\frac{h_{\text {vap }}+h_{\text {wet }}}{2}$ where,

$h_{w e t}=\left(h_{n b}^{3}+h_{c b}^{3}\right)^{\frac{1}{3}}$;

$h_{n b}=55 p r^{0.12}\left(-\log _{10}(p r)\right)^{0.55} M^{-0.5} q^{.67}$

$h_{c b}=0.0133 \operatorname{Re}_{L}^{0.69} \operatorname{Pr}_{L}^{0.4} \frac{k_{L}}{\delta}$;

$h_{v a p}=0.23 \operatorname{Re}_{G}^{0.8} \operatorname{Pr}_{G}^{0.4} \frac{k_{G}}{\delta}$;

where Reynolds number, $\operatorname{Re}=\frac{m^{\prime} d_{l}}{\mu}$ and $p r$ is the reduced pressure. The thermal resistance due to condensation is described as below:

$R_{\text {cond }}=1 / A_{c} h_{\text {cond }}$

where,

$h_{\text {cond }}=0.555\left[\frac{g\left(\rho_{l}-\rho_{v}\right) \rho_{l} k_{l}^{3}}{\mu_{l}\left(T_{s a t}-T_{s}\right)}\left(h_{f g}+\frac{3}{8} c_{p l}\left(T_{s a t}-T_{s}\right)\right)\right]^{0.25}$

for $\operatorname{Re}_{v}<35000$

The thermal resistance due to heat dissipation from the extended surfaces is described as below:

$R_{\text {diss }}=\frac{1}{h_{0}\left(\eta A_{\text {fin }}+A_{b}\right)}$

$\eta=\frac{\tanh \left(m L_{c}\right)}{m L_{c}}, m L_{c}=\sqrt{\frac{2 h_{\infty}}{k t_{f}}} L_{f}$

\section{PREPARATION OF NANOFLUIDS}

A two-step method is used to prepare the copper and aluminium nanoparticle/water mixture for the present study. Nano-particles of $99.5 \%$ purity were prepared using laser evaporation technique of $\mathrm{NaBond}$ technologies Co. and dispersed in the base fluid. De-ionized water with the required wt. per cent of nano particles are kept under ultrasonic cavitation for about 30 minutes using Ultrasonic ProcessorUP400S. The nano particles are dispersed completely after a few minutes which can be seen by the change of the colour. It is found that, both copper and aluminium nanofluids remains stable even after 48 hours. The fluid contains particle sizes of $70-130 \mathrm{~nm}$. The detail of the preparation of nanofluids are described by Shukla et al. (2010, 2012). The vapor chamber is tested within 8 hours from the time of charging of working fluids.

\section{EXPERIMENTAL SET UP}

The experimental setup consists of a vapor chamber made up of electrolytic copper of the dimensions $78 \times 64 \times 5 \mathrm{~mm}$, aluminium heat sink with the dimensions of $78 \times 64 \times 25 \mathrm{~mm}$ with thirteen fins of $23 \mathrm{~mm}$ height and $1 \mathrm{~mm}$ thickness. The top surface of the vapor chamber and the bottom surface of the heat sink were brought in to contact with the air gap between the two surfaces filled with a thermal interface material (TIM), see Fig 1. A vapor chamber heat sink was fabricated with a filling ratio of $30 \%$ of the vapor chamber volume. A copper heater block was fabricated to provide necessary heat to vapor chamber by using a stainless steel cartridge heater. Fourteen numbers $\mathrm{K}$ type thermocouples were used to measure the temperature at different locations of the vapor chamber. Five thermocouples were placed near the heater on the bottom surface of the vapour chamber to measure evaporator temperature, out of which 
one was to measure the heater temperature. Another five thermocouples were placed on the top surface of vapor chamber to measure the condenser temperature. Three thermocouples were placed on the fin surface to measure fin temperature. One thermocouple was used to measure ambient temperature. The adjacent sides of vapor chamber and the heater section were insulated by the Teflon block to ensure adiabatic conditions. All the thermocouples were connected to a PC based data acquisition system. The power supplied to the heater was calculated using the measured voltage and current supplied to the cartridge heater. A commercial $12 \mathrm{~V}$ DC fan was used for forced convection on the top of the fins.

Experiments were conducted after the installation of the test setup. In the first step the $12 \mathrm{~V} \mathrm{DC}$ fan was switched on to provide necessary cooling to the heat sink. Then the cartridge heater was turned on and the thermocouple readings were recorded by a data acquisition system connected to the computer. The heat input varied in the range of $90-150 \mathrm{~W}$.

The accuracy of the temperature measurements (K- type thermocouple) is found to be $\pm 1.5^{\circ} \mathrm{C}$. The uncertainty in the heat input is $\pm 5 \%$ for the full scale value of $250 \mathrm{~W}$. The uncertainty in the measurements of the total resistance of the vapour chamber is determined by Eq. (15) as

$\frac{\Delta R}{R}=\sqrt{\left(\frac{\Delta Q}{Q}\right)^{2}+\left(\frac{\Delta(\Delta T)}{\Delta T}\right)^{2}}$

Table 1 presents uncertainties in the thermal resistances at different heat inputs which decrease with the increase of the heat input.

Table 1 Uncertainty in the thermal resistance

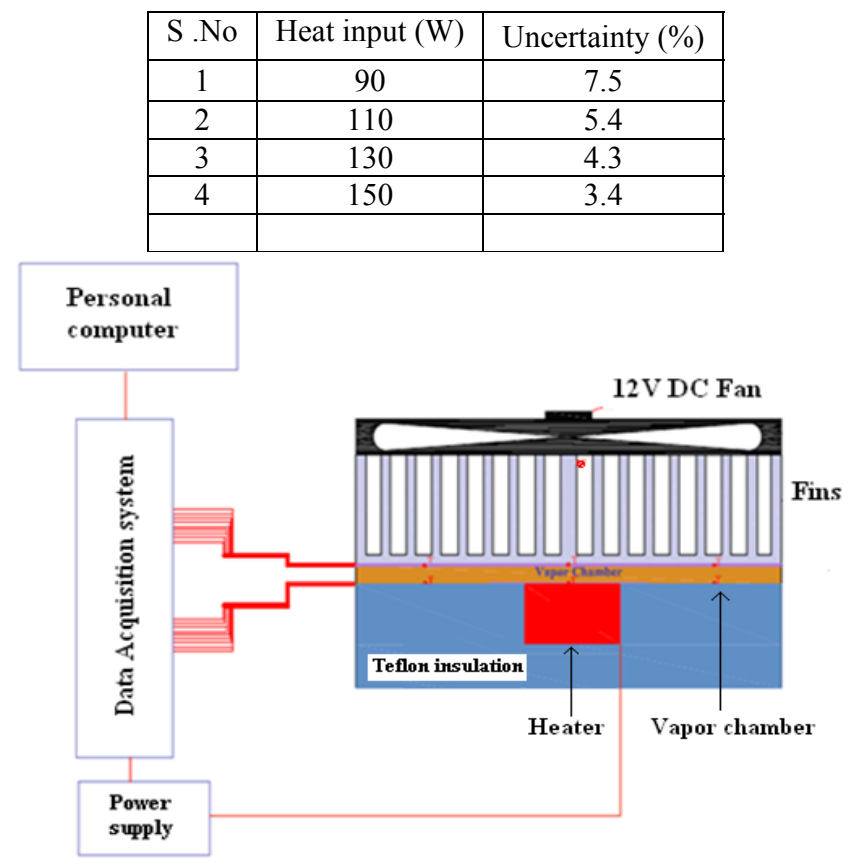

Fig. 1 Experimental setup

\section{RESULTS AND DISCUSSIONS}

The resistances expressed by the above Eq. (2), Eq. (5), Eq. (11) and Eq. (13) are calculated for Di- water and the nanofluids. These resistances are presented in Figs. (2-4). As a base line comparison, Wei et al. (2003) obtained a spreading resistance data of $0.12^{\circ} \mathrm{C} / \mathrm{W}$ for a heat source of dimensions $17 \times 17 \mathrm{~mm}$ on a vapor chamber of the dimensions $125 \times 125 \times 4.5 \mathrm{~mm}$. In the present study, a spreading resistance of $0.038^{\circ} \mathrm{C} / \mathrm{W}$ was obtained for a heat source of dimensions $35 \times 35 \mathrm{~mm}$ on a vapour chamber of smaller dimensions. The thermal resistance due to heat sink is much higher than other resistances. Thermal resistance due to boiling is lowest which shows that the liquid attains almost same temperature as wall of the vapour chamber.

The total thermal resistance $R_{t o t}$ is plotted in Fig. 4 for DIwater and the copper-water nanofluid. The total thermal resistance is lower by about $5 \%$ for the nanofluid. Thus the performance of the vapour chamber is marginally improved by the application of the nanofluid. The experimental value of the thermal resistance of the vapour chamber is calculated as below:

$R_{v}=\frac{T_{e}-T_{c}}{Q}$

where $T_{e}$ and $T_{c}$ are the average value of the evaporator and the condenser of the vapour chamber.

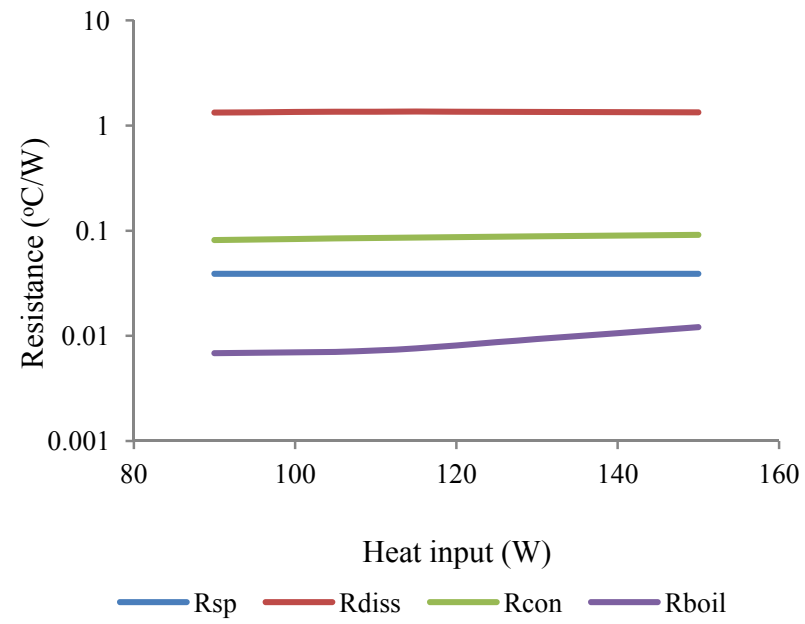

Fig. 2 Thermal resistances in vapour chamber with DI-water

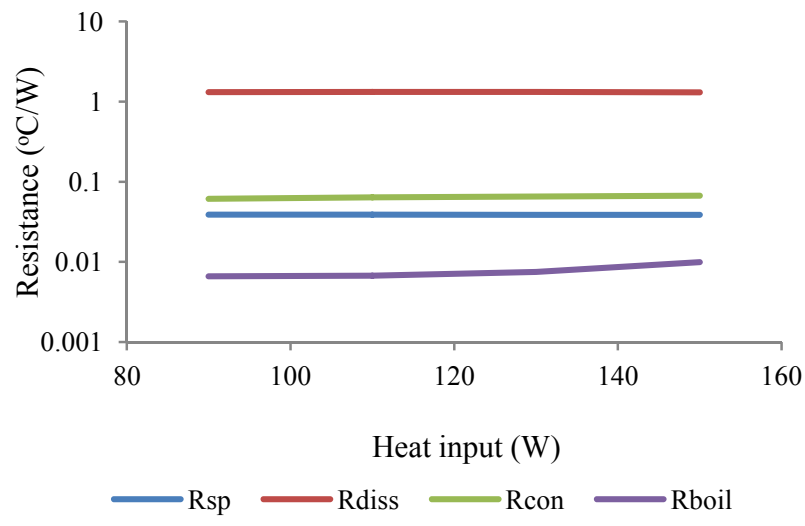

Fig. 3 Thermal resistances in vapour chamber with nanofluid

The thermal performance of the vapor chamber heat sink was investigated for high heat inputs. To ensure steady state operation, the measurements were taken when the temperatures remained steady for about 10 minutes. The total thermal resistance of the vapour chamber is calculated by Eq. (16) under steady state condition. Figure 5 presents a comparison of the experimental and analytical values of the thermal resistances of the vapour chamber without dissipation. The analytical expression under predicts the thermal resistances of the vapour chamber. The experimental values are based on the average value of the four thermocouple readings around the heater on 
the evaporator and five thermocouple readings on the condenser of the vapour chamber during steady state. The measured temperature around the heater might be higher than the actual evaporator temperature giving higher value of the thermal resistance.

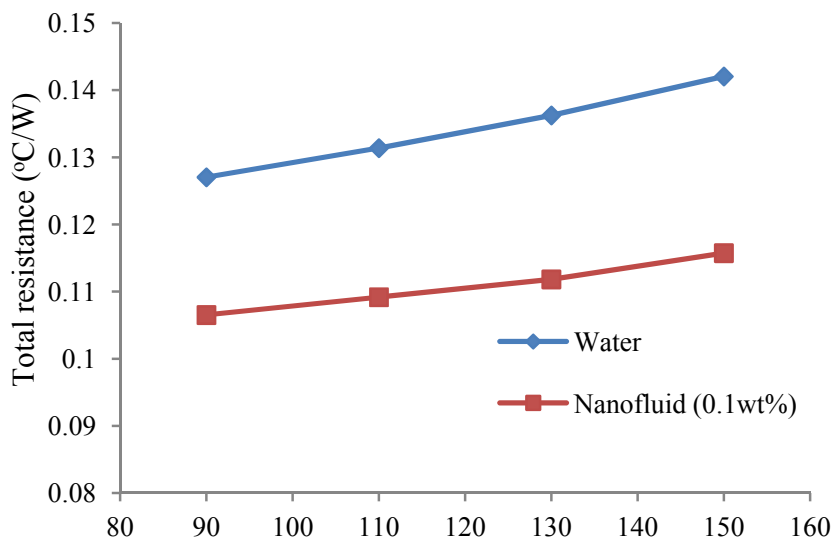

Heat input (W)

Fig. 4 Total resistance of vapour chamber without dissipation

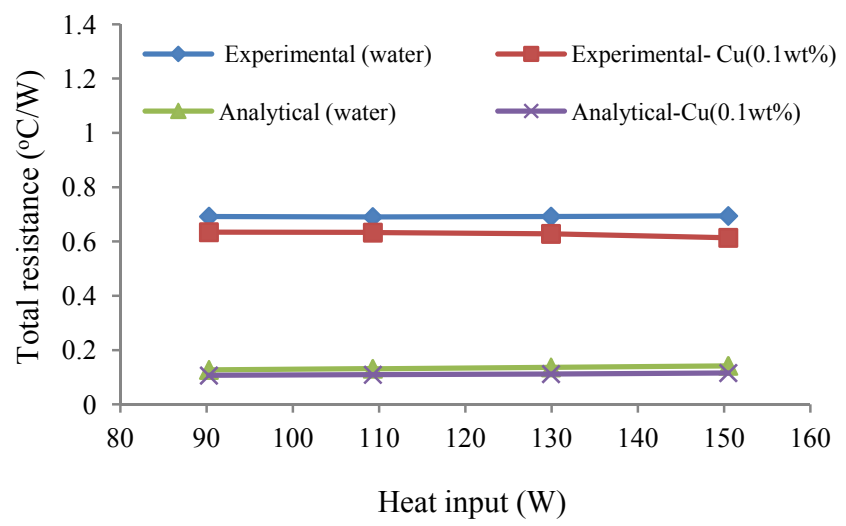

Fig. 5 Comparison of experimental and analytical values of the total thermal resistances of vapour chamber

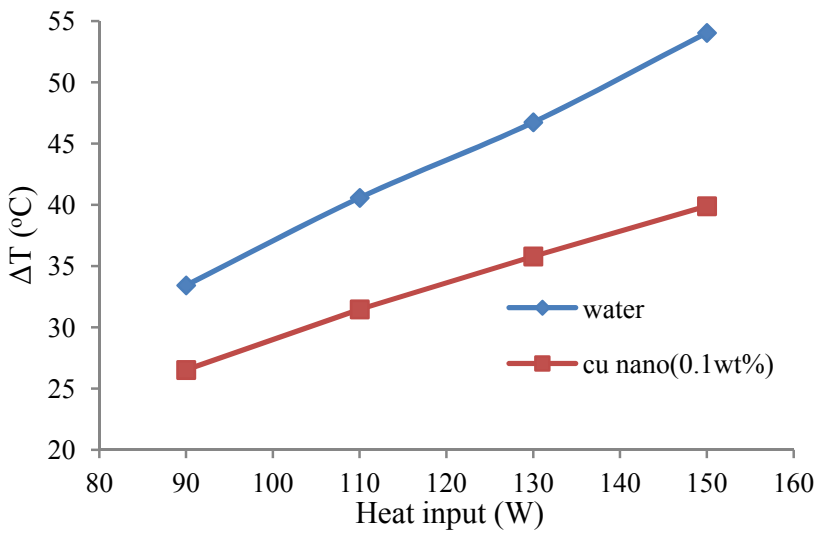

Fig. 6 Temperature drop between liquid and wall of the vapor chamber

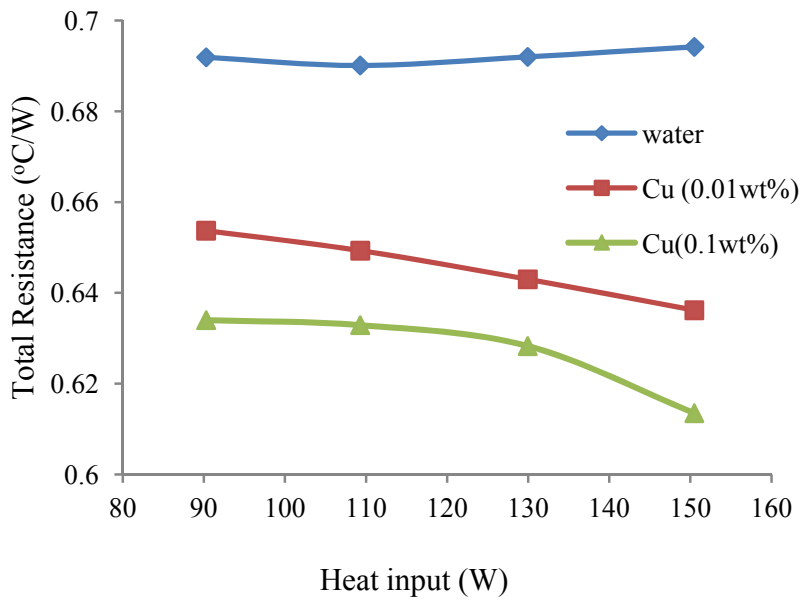

Fig. 7 Thermal resistance of integrated vapor chamber with copperwater nanofluid

The temperature drop between the vapor and the wall is calculated from the sum of the spreading and the boiling resistances and is presented in Fig. 6 for various heat input. The temperature drop in DI- water, as expected is higher than that of the nanofluid.

\subsection{EFFECT OF NANOPRTICLE CONCENTRATION}

The thermal resistances of integrated vapor chamber charged with DI-water and copper-water nanofluid at 0.01 and 0.1 wt. $\%$ are presented in Fig.7. The thermal resistance of vapor chamber is almost constant as the heat input increses for DI- water and the same is decresed as the heat input increases for copper-water nanofluids. Also, the thermal resistance is lower for higher concentration of the nanofluid. The maximum reduction in thermal resistance was found to be 8.3 and $11.6 \%$ for 0.01 and 0.1 weight $\%$ of copper nanofluid respectively. A Similar trend was observed for alminum-water nanofluid as shown in Fig. 8. The maximum thermal resistance reduces to $9.3 \%$ and $10.6 \%$ for 0.01 and 0.1 weight percent of alminum- nanofluids respectively.

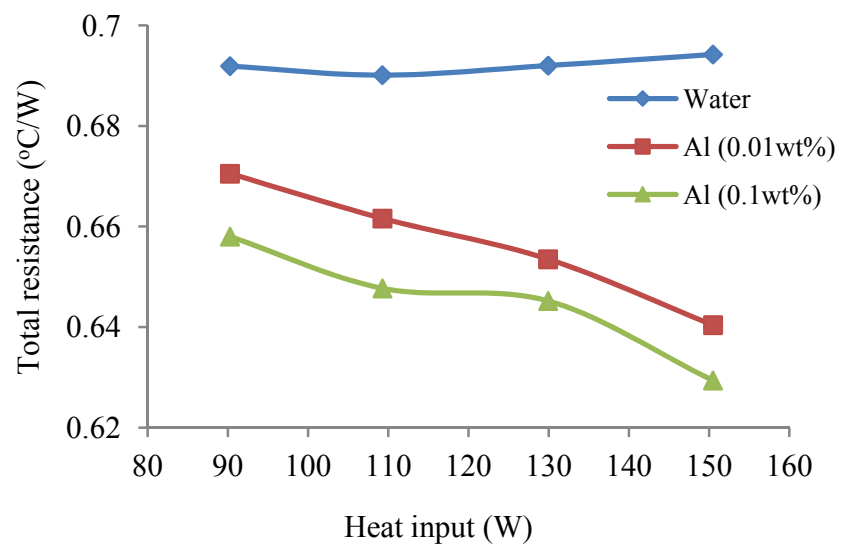

Fig. 8 Thermal resistance of integrated vapor chamber with aluminum- nanofluid.

The improvement in the thermal conductivities leads to improvement in the heat transfer capacities of the nanofluids. Shukla et al (2010) observed an enhancement of $3.79-35 \%$ in thermal conductivity for $0.01-0.1 \mathrm{wt}$. \% of nano copper particles in base water. It is quite insightful to consider the naive-idea of modelling nanofluid- thermal conductivity as a series of two layers - one of 
particle and the other of pure fluid. A very simple calculation shows that the effective thermal conductivity can be expressed as

$\frac{1}{k_{\text {eff }}}=\frac{\beta}{k_{p}}+\frac{1-\beta}{k_{l}}$

where $\beta$ is the weight fraction of the solid particle. For thermal conductivities shown in Table 2, there is an enhancement of 1 and $11 \%$ for 0.01 and 0.1 wt. \% respectively for both the aluminium and copper nanofluids. Figures (7) and (8) present almost same improvement in the thermal resistances for $0.1 \mathrm{wt}$. \% of aluminium and copper nanofluids. However for lower concentration 0.01 wt. \% of the particle, the improvement in thermal resistance is more than that of thermal conductivity. An addition of non-volatile substance increases the boiling temperature of the liquid. The lower concentration of the particles makes the nanofluid homogeneous with higher boiling point and an enhanced critical heat flux (CHF). You et al. (2003) obtained an optimum value of the concentration of the nanoparticles after which no further enhancement of the CHF was possible. The enhanced CHF may be responsible for the improvement of thermal resistance of the $0.01 \mathrm{wt} \%$ of the nanofluids.

Table 2 Thermal conductivities of water vapor and solid particles

\begin{tabular}{|c|c|}
\hline Material & Thermal Conductivity (W/m-K) \\
\hline Water Vapour & 0.016 \\
\hline Aluminium & 215 \\
\hline copper & 400 \\
\hline
\end{tabular}

\subsection{EFFECT OF NANOPRTICLE DEPOSITION}

In order to explore the reason for thermal performance enhancement in the vapor chamber, the same was opened and the evaporator surface was viewed under scanning electron microscope (SEM) after the experiments. Figure 9(a) shows the photograph of the evaporator surface of vapor chamber. Nano particle deposition was observed soon after the imitation of the boiling process. Figure 9(b \&c) shows the SEM image of porous formation at the bottom surface which is completely covered by deposition of nano particles. An irregular porous layer formed at the evaporator surface enhances wet ability and promotes dry spot- rewet ability, thus delaying the CHF (Kim et al. 2006).

To understand the effect of nanoparticle deposition on the evaporator surface of the vapor chamber, the heat transfer coefficient was evaluated by Eq. 18 at the evaporator. The heat transfer coefficient at the evaporator section of the vapor chamber is calculated as

$h_{e}=\frac{Q_{\text {in }}}{A_{e}\left(T_{e}-T_{b}\right)}$

where $T_{e}$ is the average values of the temperatures in the evaporator.

Figure 10 shows the heat transfer coefficient for various heat inputs for DI-water and copper- nano fluid. Comparisons have been made between the evaporation heat transfer coefficient of vapor chamber charged with DI- water and copper- nanofluids. Results show that the heat transfer coefficient increases linearly with the increase of the heat input. There is $15-20 \%$ increase in boiling heat transfer coefficient for the vapor chamber charged with $0.01 \mathrm{wt} \%$ copper- nanofluid as compared with DI- water. Similarly there was $30-40 \%$ enhancement in the heat transfer coefficient for $0.1 \mathrm{wt} . \%$ of copper nanofluid. As the nano particles with higher concentration form thicker porous layer compared with the nanofluids with less concentration, that causes more dry- spot rewet ability and hence the enhancement in heat transfer coefficient.
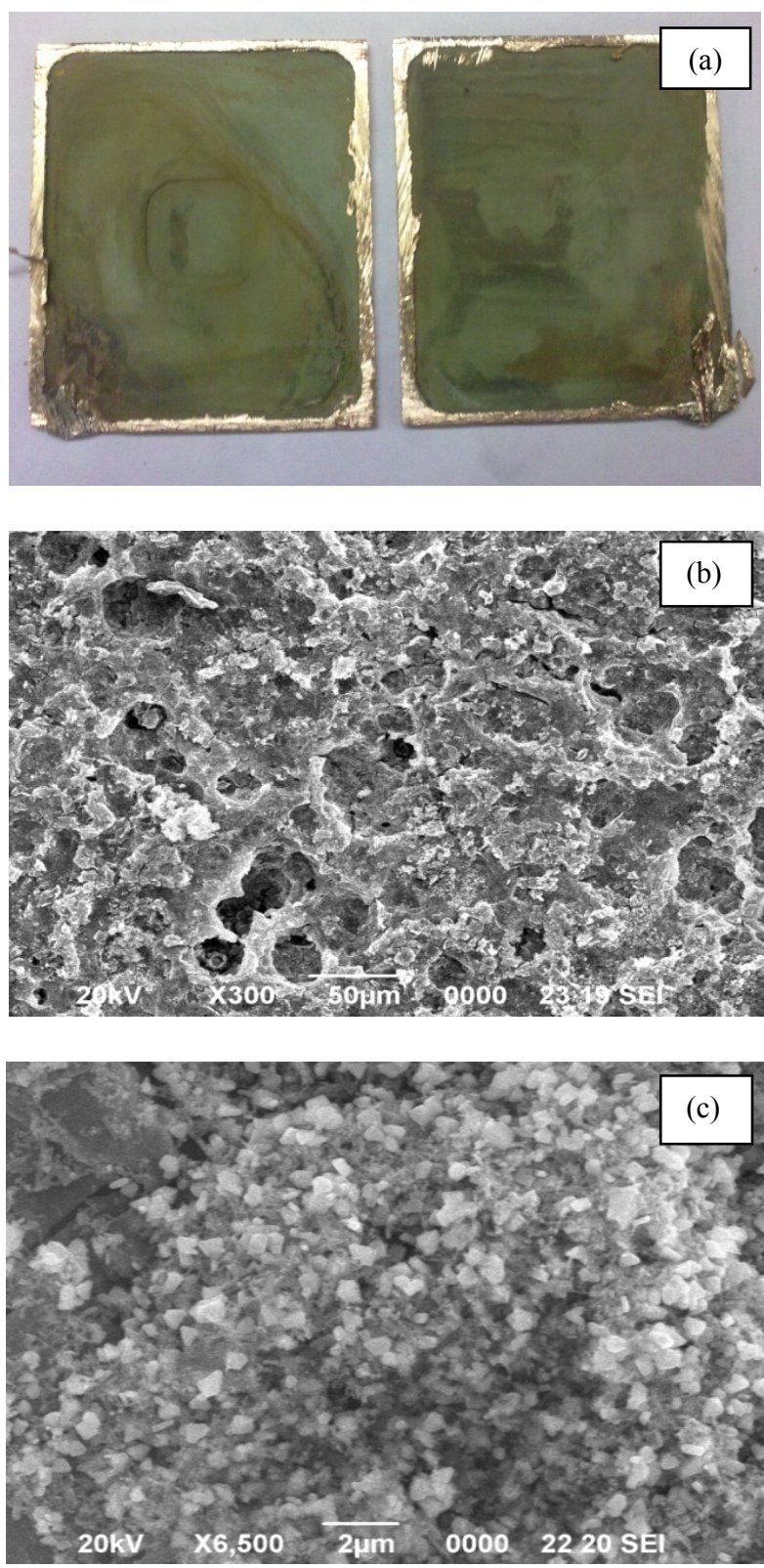

Fig. 9 View of scale formation inside vapor chamber:

(a) Photographic view, (b) SEM view at $300 \mathrm{X}$,

(c) SEM views at $6500 \mathrm{X}$

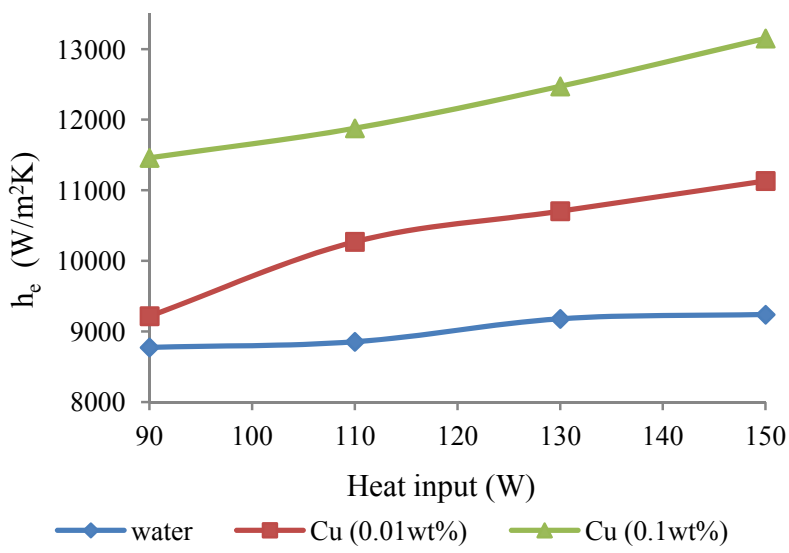

Fig. 10 Heat transfer coefficient at the evaporator 


\section{CONCLUSION}

Thermal performance of a vapor chamber with heat sink was studied by using nanofluids as working fluids. From the studies it is found that the nanofluids charged vapor chamber performs better than that charged with de-ionized water. Also found the decrease of the thermal resistances with the increase of the weight percentage of the nano particles. The copper nanofluids charged vapor chamber performs better than that charged with aluminium nanofluids and deionized water. There are many factors responsible for the heat transfer enhancement of the nanofluids. Thermal conductivity, concentration and particle densities play major role in the enhancement of heat transfer. It was also found that, the thin porous layer formed on the evaporator surface causes dry spot rewet ability and is also responsible for the heat transfer enhancement of the vapor chamber using nano fluids. The vapour chamber - heat sink with nanofluids can easily be integrated with heat dissipating components, it will have wide applications in electronics cooling.

\section{NOMENCLATURE}

A surface area $\left(\mathrm{m}^{2}\right)$

$\mathrm{C}_{\mathrm{pl}}$ specific heat of liquid $(\mathrm{J} / \mathrm{kg}-\mathrm{K})$

$\mathrm{d}$ vapour chamber thickness $(\mathrm{m})$

g acceleration due to gravity $\left(\mathrm{m} / \mathrm{s}^{2}\right)$

$\mathrm{h}$ heat transfer coefficient $\left(\mathrm{W} / \mathrm{m}^{2}-\mathrm{K}\right)$

$h_{f g}$ Latent heat of evaporation $(\mathrm{J} / \mathrm{kg})$

$\mathrm{k}$ thermal conductivity $(\mathrm{W} / \mathrm{m}-\mathrm{K})$

L length (m)

$\dot{m}$ mass flow rate $\left(\mathrm{kg} \cdot \mathrm{m}^{2} / \mathrm{s}\right)$

pr reduced pressure

Pr Prandtl number

$\mathrm{r}_{1} \quad$ equivalent radii of the base of the vapour chamber

$\mathrm{r}_{2}$ equivalent radii of the heat source

$Q$ heat transferred (W)

Re Reynolds number

$T$ Temperature (K)

$\mathrm{t}$ thickness of the plate $(\mathrm{m})$

Greek Symbols

$\rho$ density $\left(\mathrm{kg} / \mathrm{m}^{3}\right)$

$\mu \quad$ dynamic viscosity (Pa.s)

$\eta \quad$ fin efficiency

$\tau$ dimensionless thickness of the base plate $\left(t / r_{2}\right)$

$\varepsilon \quad$ dimensionless contact radii $\left(\mathrm{r}_{1} / \mathrm{r}_{2}\right)$

$\delta \quad$ film thickness (m)

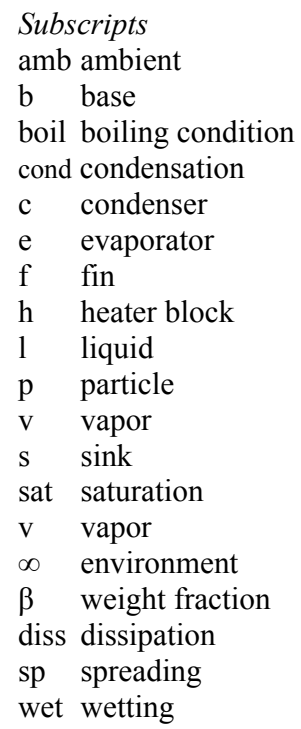

\section{REFERENCES}

Carbajal, C., Sobhan, C. B., Peterson, G. P., Queheillalt, D. T., Wadley, H. N .G., 2006, "Thermal Response of a Flat Heat Pipe Sandwich Structure to a Localized Heat Flux," International Journal of Heat and Mass Transfer, 49, 4070-4081.

http://dx.doi.org/10.1016/j.ijheatmasstransfer.2006.03.035

Choi, U. S., 1995, "Enhancing thermal Conductivity of Fluids with Nanoparticles," ASME FED, 231, 99-103.

Cooper, M. G., 1984, "Saturation Nucleate Pool Boiling," Ist UK National Conference on Heat Transfer, 2, 785-793 (Industrial and Chemical Engineering Symposium Series No. 86)

Do, K. H., Jang, S. P., 2010, "Effect of Nanofluids on the Thermal Performance of a Flat Micro Heat Pipe with a Rectangular Grooved Wick," International Journal of Heat and Mass Transfer, 53, 21832192. http://dx.doi.org/10.1016/j.ijheatmasstransfer.2009.12.020

Go, J. S., 2005, "Quantitative Thermal Performance Evaluation of a Cost-Effective Vapor Chamber Heat Sink Containing a Metal-etched Micro Wick Structure for Advanced Microprocessor Cooling," Sensors and Actuators: A Physical, 121, 549-556. http://dx.doi.org/10.1016/j.sna.2005.03.007

Kattan, N., Thome, J.R., Favrat, D., 1998, "Flow Boiling on Horizontal Tubes, Part I: Development of Adiabatic Two-Phase Flow Patterns," ASME Journal of Heat Transfer, 120, 156-165. http://dx.doi.org/10.1115/1.2830037

Kang, S. W.,Chen, Y. T., Hsu, C.H., Lin, J. Y., 2012,“Temperature Uniformity Analysis of a Multi-well Vapor Chamber Heat Spreader," Frontiers in Heat Pipe FHP, 3, 013004.

http://dx.doi.org/10.5098/fhp.v3.1.3004

Kim, S.J., Bang, I. C., Baongiorno, J., Hu, L. W., 2006, "Effects of Nanoparticle Deposition on Surface Wettability Influencing Boiling Heat Transfer in Nanofluids," Applied Physics Letters., 89(15), 153107-1-3.

http://dx.doi.org/10.1063/1.2360892

Liu, Z., Xiong, J. G., Bao, R., 2007, "Boiling Heat Transfer Characteristics of Nanofluids in a Flat Heat Pipe Evaporator with Micro-Grooved Heating Surface," International Journal of Multiphase Flow, 33, 1284-129.

http://dx.doi.org/10.1016/j.ijmultiphaseflow.2007.06.009

Ming, Z., Zhongliang, L.,Guoyuan, Ma , 2009, "The Experimental and Numerical Investigation of a Grooved Vapor Chamber," Applied Thermal Engineering , 29, 422-430.

http://dx.doi.org/10.1016/j.icheatmasstransfer.2008.07.010

Naphon, P., Assadamongkol, P., Borirak, T., 2008, "Experimental Investigation of Titanium Nanofluids on the Heat Pipe Thermal Efficiency," International Communications in Heat and Mass Transfer, 35, 1316-1319. http://dx.doi.org/10.1016/j.icheatmasstransfer.2008.07.010

Nguyen, T., Mochizuki, M, Mashiko, K, Saito, Y, 2000, “Use of Heat Pipe/ Heat Sink for Thermal Management of High Performance CPU's," Proc. $16^{\text {th }}$ IEEE Semi-Therm Symposium, 76-79. http://dx.doi.org/ 10.1109/STHERM.2000.837064

Qu, J. H., Wu, Y., Cheng, P., 2010, "Thermal Performance of an Oscillating Heat Pipe with Al2O3-Water Nanofluids," International Communications in Heat and Mass Transfer, 37, 111-115. http://dx.doi.org/10.1016/j.icheatmasstransfer.2009.10.001

Shukla, K. N., 1981," Transient Response of a Gas-Controlled Heat Pipe," AIAA Journal, 19(8), 1063-1070. 


\section{http://arc.aiaa.org/doi/abs/10.2514/3.7842}

Shukla, K. N., 2008," Thermo Fluid Dynamics of Loop Heat Pipe Operation," International Communications in Heat and Mass Transfer, 35, 916-920.

http://dx.doi.org/10.1016/j.icheatmasstransfer.2008.04.020

Shukla, K. N., 2009, "Heat Transfer Limitation of a Micro Heat Pipe," ASME Journal of Electronic Packaging. 13, 024502. http://dx.doi.org/10.1115/1.3103970

Shukla, K. N., Solomon, A. B., Pillai, B. C., 2009, "Experimental Studies on Rotating Heat Pipe," Heat Transfer-Asian Research, 38(8), 475-484.

http://dx.doi.org/10.1002/htj.20265

Shukla, K. N., Solomon, A. B., Pillai, B. C., Ibrahim, M., 2010, "Thermal Performance of Cylindrical Heat Pipe Using Nanofluids," Journal of Thermophysics and heat Transfer, 24,796-802. http://dx.doi.org/ 10.2514/1.48749

Shukla, K. N., Solomon, A. B., Pillai, B. C., Jacob Ruba Singh, B., Kumar, S. S., 2012, "Thermal Performance of Heat Pipe with Suspended Nanoparticle," Heat and Mass Transfer, 48 (11), 19131920.

http://dx.doi.org/10.1007/s00231-0125-1028-4

Simons, R. E., 2004, "Simple Formulas for Estimating Spreading Thermal Resistance," Electronics Cooling, 10(2), 8-10
Wang, Y., Vafai, K., 2000, “An Experimental Investigation of the Thermal Performance of an Asymmetrical Flat Plate Heat Pipe," International Journal of Heat and Mass Transfer, 43, 2657-2668. http://dx.doi.org/10.1016/S0017-9310(99)00300-2

Wei, J., Cha, A., Copeland, D., 2003, "Measurement of Vapour Chamber Performance," IEEE, Semi-Therm Symposium, 191-194. http://dx.doi.org/ 10.1109/STHERM.2003.1194361

Wong, S-C., Hsieh, K- C., Wu, J.-D. , Han, W.-L., 2010, “A Novel Vapor Chamber and Its Performance," International Journal of Heat and Mass Transfer, 53, 2 377-2 384.

http://dx.doi.org/10.1016/j.ijheatmasstransfer.2010.02.001

Xuan, Y., Hong,Y., Li, Q, 2004, "Investigation on Transient Behaviours of Flat Plate Heat Pipes," Experimental Thermal and Fluid Science, 28, 249-255. http://dx.doi.org/10.1016/S0894-1777(03)00047-5

Yang, X. F., Liu, Z. H., Zhao, U. J. F., 2008, "Heat Transfer Performance of a Horizontal Micro Grooved Heat Pipe Using $\mathrm{CuO}$ Nanofluid," Journal Micromechanics and Microengineering, 18, 035038.

http://dx.doi.org/10.1088/0960-1317/18/3/035038

You, S. M., Kim, J. H., Kim, K. H., 2003, "Effect of Nanoparticles on Critical Heat Flux of Water in Pool Boiling Heat Transfer," Applied Physics Letters. 83, 3374-3376.

http://dx.doi.org/10.1063/1.1619206 